\title{
Carbon Nanotubes and Graphene Radiant Heater Printed on a Cementitious Flooring Substrate: A Feasibility Study
}

\author{
John Patsavellas ${ }^{a^{*}}$, Konstantinos Salonitis ${ }^{\mathrm{a}}$, Krzysztof Koziol ${ }^{\mathrm{a}}$, Lukasz Zakrzewski ${ }^{\mathrm{a}}$, \\ Ben Blackwood ${ }^{b}$ \\ ${ }^{a}$ Manufacturing Theme, Cranfield Univeristy, Cranfield, Bedfordshire, MK43 0AL, England, \\ ${ }^{b} 17$ Snowdonia Way, SG1 6GU \\ * Corresponding author. Tel.: +44(0) 1234 754589. E-mail address: John.Patsavellas@cranfield.ac.uk
}

\begin{abstract}
The human activity of heating homes contributes a significant amount of $\mathrm{CO} 2$ in the total of the UK Green House Gases and the process of retrofitting residential stock and equipping new dwellings with lower and carbon neutral technologies could be complex, costly and physically challenging. This paper investigates the feasibility of a composite mixture of carbon nanotubes (CNT) and graphene material applied as a printed layer to the underside of a cementitious flooring substrate, acting as a radiant underfloor heater. Screening sample tests confirm instant radiant heating at low DC voltages with remarkably low conduction heat losses through the substrate.
\end{abstract}

Keywords: Graphene; Nanotubes; sustainable heating; flooring

\section{Introduction}

As the world is attempting to re-orient its focus on technologies that can enable decarbonisation of human activity, a plethora of new materials, technologies and products are being assessed for improved energy efficiency in different sectors of human economic activity.

In the UK, according to the latest published data (BEIS, 2020) [1], the residential sector accounts for $15 \%$ of all Green House Gas Emissions (GHG) which is equivalent to the whole of the UK's Power Generation emissions. The majority of the residential sector's GHG is due to heating which is primarily $\mathrm{CO} 2$ emissions from the use of natural gas as fuel for central heating boiler installations in UK homes. Given the commitment enshrined in UK law in June 2019 to achieve $100 \%$ reduction of GHG emissions ("net zero") by 2050 [2], reducing emissions would probably require changes in the way residential homes are heated [3]. To that end the UK government has already announced its intention to ban the use of fossil fuel heating systems in all new houses from 2025 [4]. This presents a number of challenges in terms of the technology, time and complexity of coming up with new, lower carbon heating solutions for new homes notwithstanding concerns on cost given that heating dwellings in winter in the UK, makes up about $60 \%$ of an average household's energy bills $[5,6]$. On the other hand, retrofitting the vast existing housing stock with new heating technologies that meet safety, cost, complexity, time, choice and well-being expectations, could become a significant barrier on the roadmap to net zero [7].

The technology pathways at the forefront of decarbonizing residential heating are electricity and hydrogen [7]. On the electricity front, the low carbon heating technology that has received the most publicity is air-source heat pumps (ASHP) [8]. The carbon footprint of a typical ASHP -depending on the nature of the its electricity supply-, is estimated at a range of 60-170 grams of carbon dioxide equivalent per kilowatt-hour of heat ( $\mathrm{gCO} 2 \mathrm{eqkWh}$ ), versus 210-380 gCO2eqkWh for a typical natural gas boiler in a residential heating installation system [9].

The complexity of decarbonising residential heating however, would require a diversity of complementary technologies in order to provide flexible and tailored heating to different builtenvironment settings. Air-to water heat pumps can be used successfully to generate hot water stored in a hot cylinders, but require expensive and physically challenging wet underfloor heating installations for space heating [10] which may limit their practicality and deployment, especially in retrofit scenarios.

The present paper will report a first attempt to use advanced composites such as carbon nanotubes and graphene as heating elements. A feasibility study is presented, and a set of screening experiments were performed for proof of concept. In the following sections, the benefits of such materials for such applications are presented. Then the experimental setup is described, and the experimental results are analysed and discussed. 


\section{Alternative heating technologies based on CNT and Graphene}

A novel technology to be considered for residential heating is an array of very thin printed layers of a mixture of carbon nanotubes (CNT) and graphene materials, acting as electrically-powered radiant heat emitters positioned under the floor, wall and ceiling substrates/coverings in the built environment.

CNTs which were discovered by Iijima (back in 1991) $[11,12]$ are microtubules of graphitic carbon consisting of two or more seamless graphene cylinders arranged concentrically [13]. CNTs have been found to be thermally stable and have been used in varied applications due to their remarkable physical and chemical properties which include electrical conductivities of up to $10^{5} \mathrm{Scm}^{-1}$ and current densities up to a level of $10^{6} \mathrm{Acm}^{-2}[14,15]$.

Graphene, a two-dimensional form a crystalline honeycomb structured carbon material discovered by Noveselov et al. [16, 17] and reported to be the strongest material ever discovered by humankind [15] also exhibits good conductivities of up to 6300 $\mathrm{Scm}^{-1}[18,19]$ in a multilayer graphene (MLG) format. Depending on its resistivity, MLG can also reach current-carrying capacities of up to $\sim 1.6 \times 10^{9}$ $\mathrm{Acm}^{-2}$ which is several orders higher than that of copper [20]. According to Geim and Novoselev [21], a two-dimensional single-layered graphene can be rolled up into a hollow cylindrical structure to from a one-dimensional CNT with its honeycomb structure intact. As each carbon atom has four electrons in the outer shell and only three are used to form covalent bonds, the remaining free electron renders graphene and CNTs highly electrically conductive. Furthermore, as observed by Nan et al. [22], creating a nanocomposite mixture of CNT and graphene can increase conductivity dramatically due to the so called percolation phenomenon which is governed by the geometric structure contrast (two vastly different kinds of aspect ratios) of CNTs and graphene. This means that highly desirable nanocomposites with very high conductivity can be achieved with only a small amount of CNT or graphene loading in the mixture [23]. When the right formulation of CNT and graphene can be dispersed in an ink carrier, the resulting suspension can provide a highly conductive printable film which can be deposited by an appropriate printing method (spraypainting, inkjet, screen, gravure or flexo) as a film on a given substrate $[24,25]$. The dried printed film can then act as a heater due to the fact that upon application of appropriate voltage across its surface, the collisions of electrons and phonons produce instant heat, a phenomenon called Joule heating [26]. These heaters according to Larciprete et al. [27] demonstrate efficient heat release due to high radiation along with low resistance, an average IR emissivity $>0.5$ in a wide wavelength range (4-14 $\mu \mathrm{m})$ rendering them very effective radiant heaters.

Given the need for alternative solutions with regards to lower energy and easier installation of underfloor heating in the built environment, such radiant heaters could be of significant benefit due to their space-saving potential (printed films of 10-100 microns thickness) their reduced energy consumption and instantaneous emission of radiant heat energy. Floor Heating $(\mathrm{FH})$ radiant systems are becoming increasingly desirable by specifiers and consumers due to their reputation for better thermal comfort in comparison to convective heat (AC units), by providing a more stable thermal comfort due to the minimisation of draft and vertical temperature differences [28].

From the environmental point of view, a life cycle analysis of graphene as a heating element was performed [29]. The study was focused on the process steps required for the production of graphene ink and calculated that for every $\mathrm{kg}$ of graphene ink, 142-154 MJ of energy is consumed. However, there is still no study of the environmental impact of a CNT and graphene manufacturing.

\section{CNT \& graphene heater on a cementitious flooring substrate sample}

The potential of a radiant printed heater comprising of CNT and graphene was tested on a patented $8 \mathrm{~mm}$ thick cementitious board, comprising primarily of calcium silicate. The specific board was chosen due to its superior mechanical and fireresisting properties as opposed to any other flooring substrate. A $50 \mathrm{~cm}^{2}$ area of the underside of the board was spray-printed with a proprietary CNT and graphene nanocomposite film. For delivering the current to the film, copper electrodes were used. Figure 1 shown the printed board.

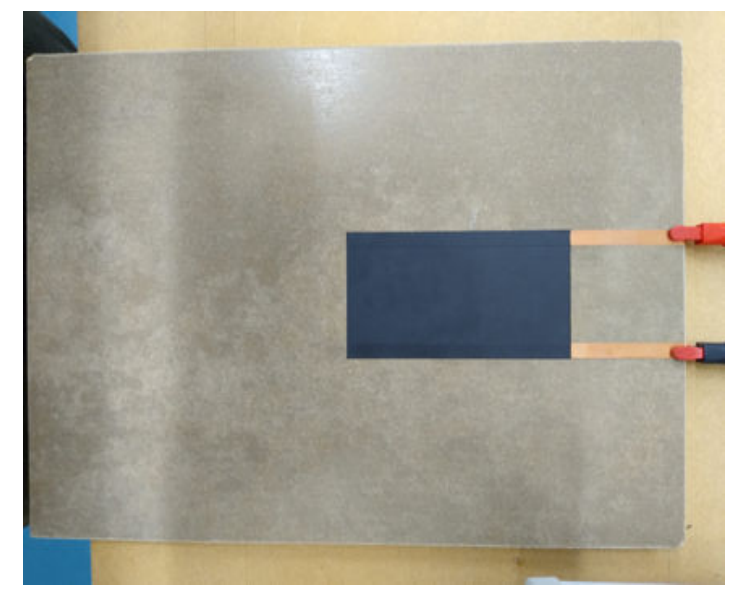

Fig. 1. Printed board with a composite of CNT and graphene. 


\subsection{Materials and methods}

The heater was produced by spray-printing the CNT-graphene ink, with the final composition of $60 / 40$ of CNT/Graphene mixture. The ink was prepared using isopropanol as the matrix following by 5 minutes sonication process.

Carbon nanotubes were synthesized in our laboratory by chemical vapour deposition (CVD) process using 6 wt.\% ferrocene/toluene feedstock and silica substrates at $760{ }^{\circ} \mathrm{C}$ in argon atmosphere [30]. The mean outer and inner diameters of the multi-walled CNTs were $60 \pm 25$ and $10 \pm 2 \mathrm{~nm}$, respectively. Figure 2 show a representation of the material under scanning electron microscopy (SEM)

Fig. 2. Heater material view under SEM.

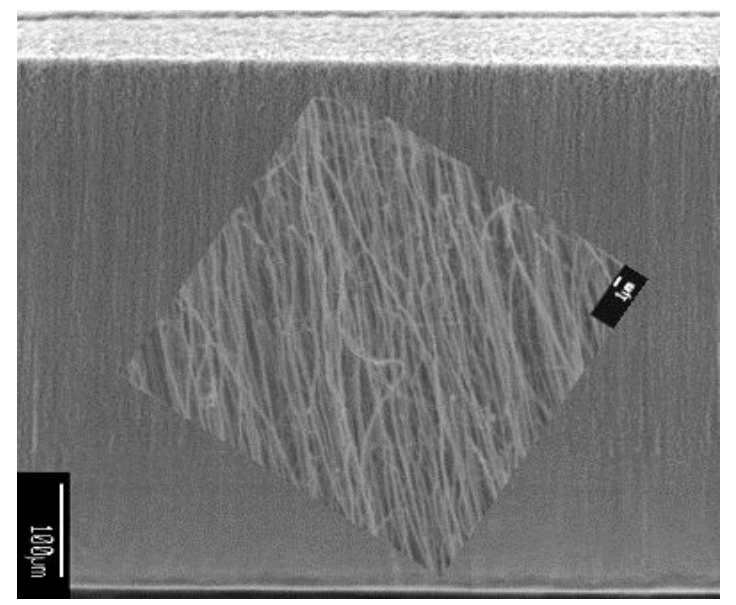

Graphene flakes used in the present work were produced by Cambridge Nanosystems Limited, and are commercially available under the brand name CamGraph (G3). According to the ISO/TS8000413:2017 norm these graphene flakes are defined as few-layer graphene. Figure 3 shows a representation of the material under transmission electron microscopy (TEM).

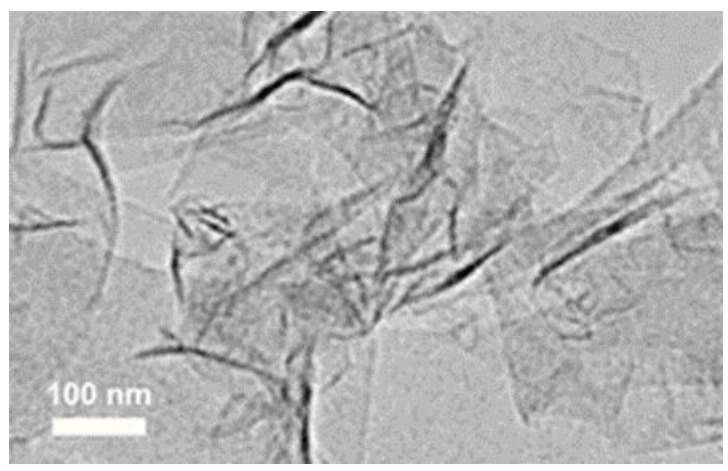

Fig. 3. Heater material view under TEM.

\section{Experimental design and setup}

The focus of the experimental setup was to assess how the printed heating board behaves under different values of voltage (electric potential difference), using a direct current (DC) source. For this reason, a variable DC power supply was used, capable of regulating voltage precisely in the range of $0-30 \mathrm{~V}$. The printed board was connected to the supply through alligator clip leads.

For monitoring the temperature, a thermal imaging camera was used (FLIR T440) that features a $230 \times 24060 \mathrm{~Hz}$ infrared (IR) detector, with a thermal sensitivity of $0.04^{\circ} \mathrm{C}$ and a -20 to $1,200{ }^{\circ} \mathrm{C}$ temperature measurement range.

After a short number of screening experiments, the voltage range was set to be from 4 to $14 \mathrm{~V}$. However, a small set of experiments was also performed at higher voltage values to assess the printed board integrity under extreme conditions. Finally, all experiments were repeated three times, and the temperature was measured both from the front side of the board (printed side) and the back side. As such printed boards would be used for heating, they would be printed at the lower side of the board. The flow of the heat as well as the speed of the heating is important. In figure 4 , the experimental setup is shown.

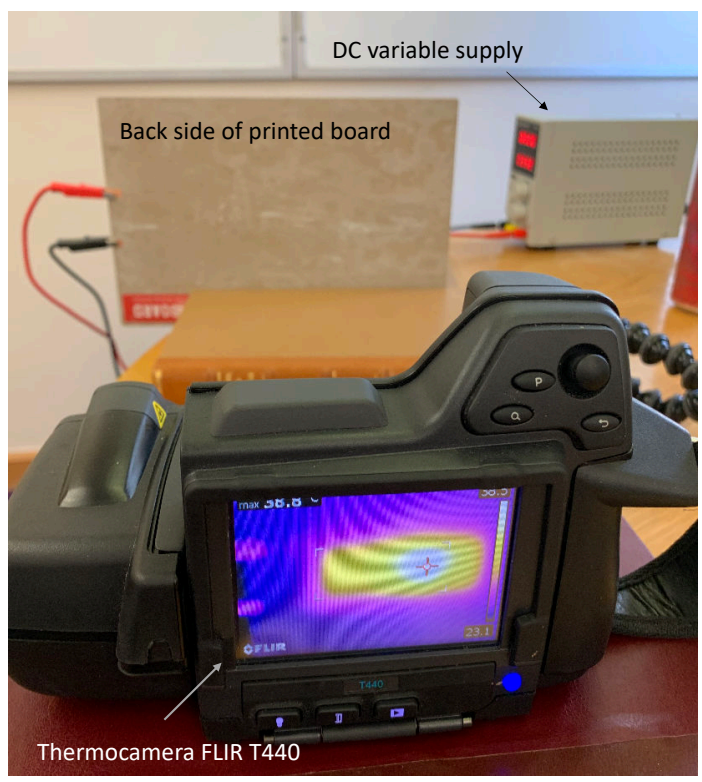

Fig. 4. Experimental setup.

\section{Experimental Results and Discussion}

The temperature was measured every minute using the thermo-camera after the supply of the voltage was initiated. Before the start of each experiment, the board and heating printed element was brought to ambient environmental temperature. 
Figure 5 presents the results. As it can be seen, the experiment at the highest voltage was stopped once the surface temperature exceeded $100{ }^{\circ} \mathrm{C}$.

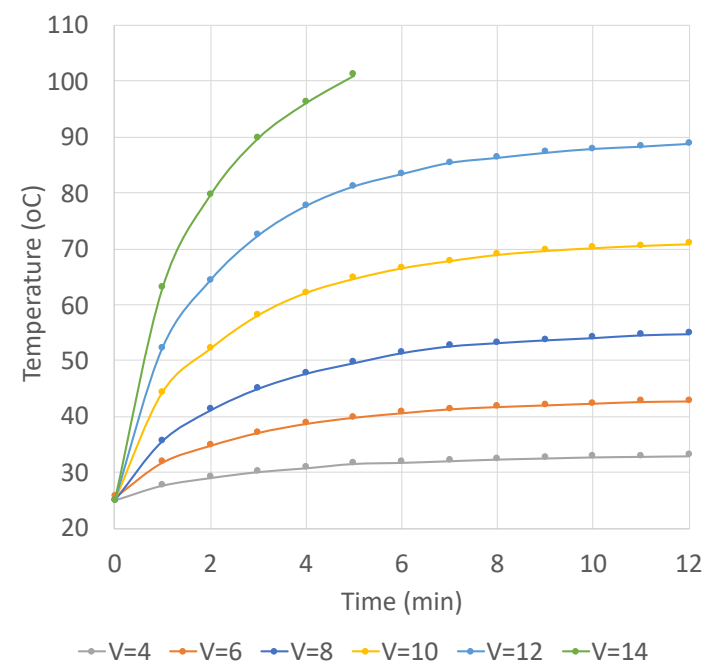

Fig. 5. Experimental results: temperature as a function of time.

As it would be expected, the surface temperature increases asymptotically to a maximum value as time elapses. The higher the voltage value, the higher the maximum temperature reached as can be seen in both figures 5 and 6 . A notable characteristic of such heating material is the speed with which it heats up. In all of the experiments, the surface temperature of the heating element reached $90 \%$ of its maximum temperature within 5 minutes, and $99 \%$ of its maximum temperature within 9 minutes.

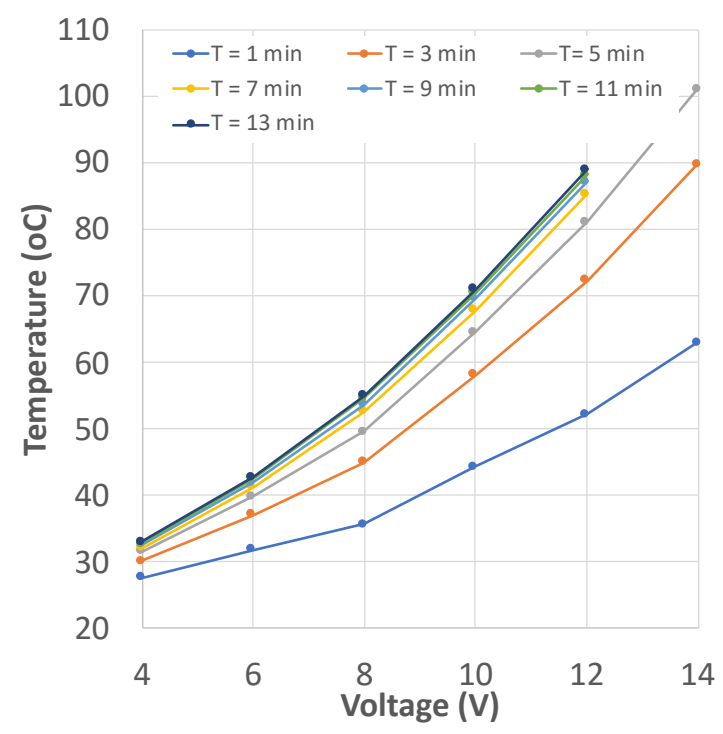

Fig. 6. Experimental results: temperature as a function of voltage.

In traditional wet underfloor heating applications, the expected temperature of the water is in the range of 35 to $60^{\circ} \mathrm{C}$ depending on heat losses from the building. The setting of the water flow temperature depends also on whether the floor is screeded, suspended or floating. Such temperatures as can be seen from figures 5 and 6 are easily achievable in the experimental rig with low voltage values. As each experiment was repeated three times, the repeatability of the results was in the order of $95 \%$. This highlights the ease of control of the temperature to be achieved.

During each experiment, the current value was monitored and recorded as well. The current value was steady for each voltage value (with minor fluctuations within $\pm 5 \%$ of the value reported). Figure 7 presents the results, indicating a linear relationship between the voltage applied and the current recorded. On the other hand, the electrical resistance of the heat element is calculated from the current and the voltage values. Figure 8 shows that the resistivity drops as the voltage value is increased. This is most likely to be attributed to the higher temperature achieved, and the dependence of the physical and electrical properties of graphene and CNT to the temperature.

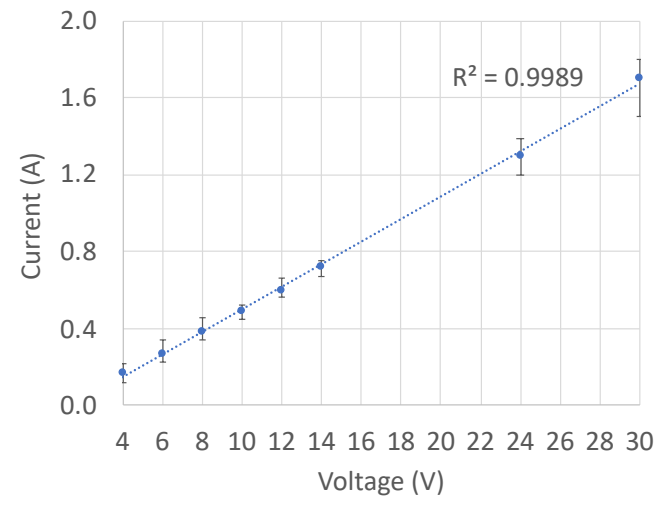

Fig. 7. Experimental results: Current value as a result of voltage.

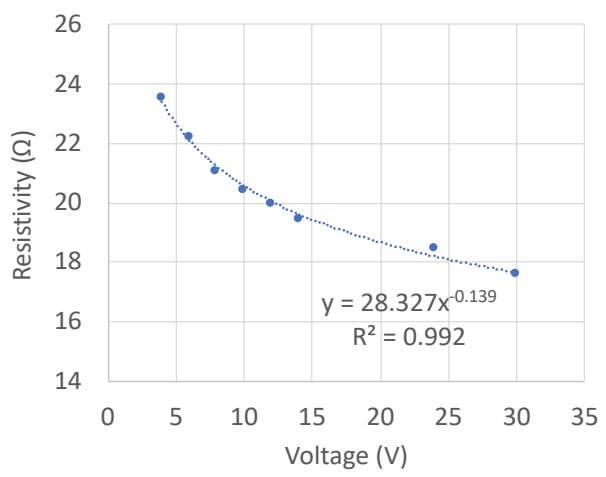

Fig. 8. Experimental results: Current value as a result of voltage.

As mentioned in the experimental setup, for such a heating element to efficiently work, the heat needs 
to "pass through" the board. For this reason, the surface temperature was measured from both sides of the board as it can be seen in in figure 9. For low voltage values, the difference between the two sides drops below $3 \%$ within three minutes. This highlights the excellent radiant heat transmissibility and thermal conductivity properties of the specific cementitious board.

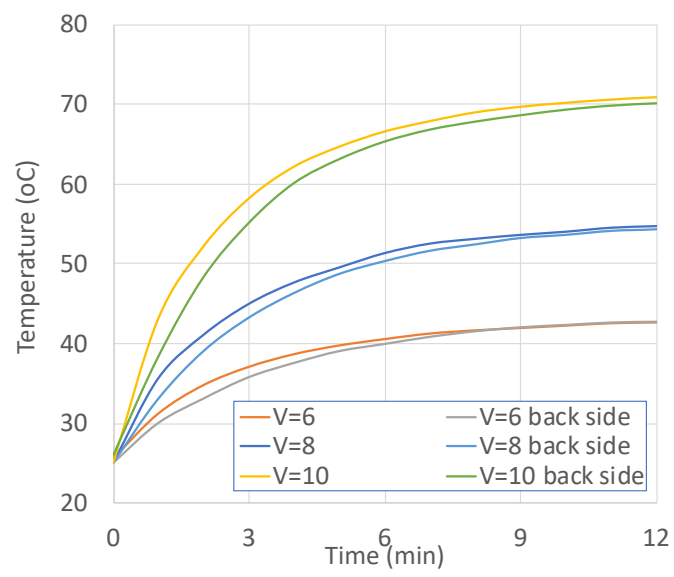

Fig. 9. Experimental results: surface temperature from both sides of the board.

Finally, a voltage of $30 \mathrm{~V}$ was used in order to assess how the specimen will work under extreme conditions. The temperature reached $150^{\circ} \mathrm{C}$ within $15 \mathrm{sec}$. At that temperature level, blisters appeared on the surface of the printed board as seen in Figure 10. Such a result highlights the operational range of such material, with possible need for further tailoring of the heater ink formulation for higher operational temperatures.
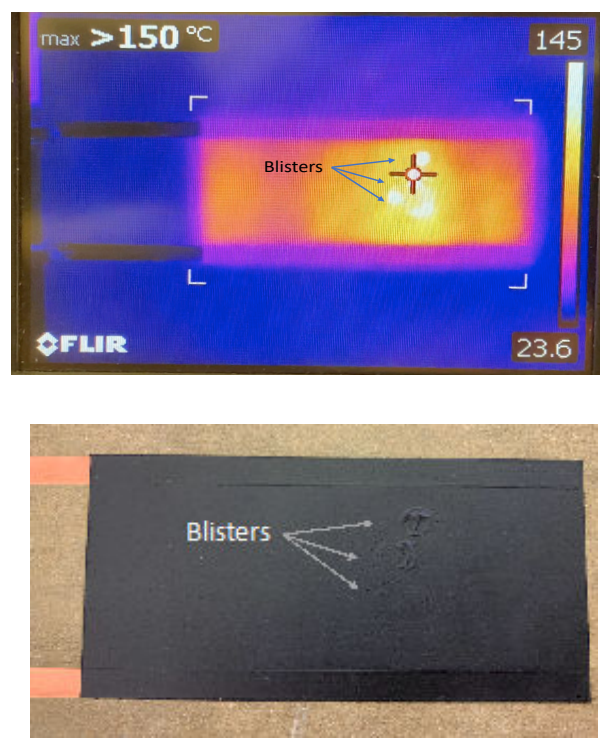

Fig. 10. Maximum surface temperature achieved and degradation of material.

\section{Conclusions}

In the present paper, a feasibility study was presented for using a Carbon Nanotubes and Graphene radiant heater printed on a cementitious flooring substrate. The experimental design proved that such a combination can be used as an alternative to traditional underfloor heating. Through the experimental results the operational limits of such combination were explored. The authors foresee further experimentation to be undertaken, focusing on the impact of deposition techniques as well as the design of the heating pattern on the efficiency of the heating.

\section{Acknowledgements}

The authors would like to acknowledge BlazeBoard Ltd. for supplying the decking boards for experimentation.

\section{References}

[1] Department for Business energy and Industrial Strategy, (2020) 2018 UK Greenhouse Gas Emissions, Final figures. Available at: https://www.gov.uk/government/statistics/final-ukgreenhouse-gas-emissions-national-statistics-1990to-2018 (Accessed: 9 September 2020)

[2] UK Parliament (2019), Net zero in the UK. Available at: https://commonslibrary.parliament.uk/researchbriefings/cbp-8590/ (Accessed

[3] Climate Assembly UK (2020), The path to net zero. Available at: https://www.climateassembly.uk/report/ (Accessed: 10 September 2020).

[4] Gov.uk, (2019) Spring Statement 2019: what you need to know. Available at: https://www.gov.uk/government/news/springstatement-2019-what-you-need-to-know (Accessed: 10 September 2020).

[5] Department for Business energy and Industrial Strategy, (2017) Heat in Buildings, Boiler Plus. Available

at: https://assets.publishing.service.gov.uk/government/u ploads/system/uploads/attachment_data/file/651853/ Boiler_Plus_final_policy_and_consultation_response .pdf (Accessed: 9 September 2020).

[6] Department for Business energy and Industrial Strategy, (2019) Energy consumption in the UK. Available at: https://www.gov.uk/government/statistics/energyconsumption-in-the-uk (Accessed: 26 August 2020).

[7] Net-Zero Infrastructure Industry Coalition, (2020) The path to zero carbon heat. Available at: http://www.mottm.ac/hsQX50ACWC1 (Accessed: 10 September 2020)

[8] Committee on Climate Change, (2019) Net Zero Technical Report. Available at: 
https://www.theccc.org.uk/publication/net-zerotechnical-report/ (Accessed: 9 September 2020)

[9] Parliamentary Office of Science and Technology, (2016) Carbon Footprint of Heat Generation. Available at: http://researchbriefings.files.parliament.uk/document s/POST-PN-0523/POST-PN-0523.pdf (Accessed: 9 September 2020)

[10] GreenMatch.co.uk (2020) Pros and Cons of Air Source Heat Pumps. Available at: https://www.greenmatch.co.uk/blog/2016/02/prosand-cons-of-air-source-heatpumps\#: :text=An\%20air\%20source $\% 20$ heat $\% 20$ pu mp $\% 20$ (ASHP) $\% 20$ works $\% 20$ by $\% 20$ transferring $\% 2$ 0heat,transfer $\% 20$ it $\% 20$ to $\% 20$ another $\% 20$ medium. (Accessed: 11 September 2020)

[11] Iijima, S., 1991. Helical microtubes of graphitic carbon", Nature, 354 (6348): 56-58. https://doi.org/10.1038\%2F354056a0

[12] Iijima, S., Ichihashi, T., 1993. Single-shell carbon nanotubes of 1-nm diameter, Nature. 363 (6430): p. 603-605. doi:10.1038/363603a0

[13] Iijima, S., 2002. Carbon nanotubes: past, present, and future, Physica B 323 p.1-5.

[14] Wei, B., Vajtai, R., Ajayan, P., 2001. Reliability and Current Carrying Capacity of Carbon Nanotubes, Applied Physics Letters, 79. p. 1172-1174.

[15] Sun, X., Sun, H., Li, H., Peng, H., 2013. Developing Polymer Composite Materials: Carbon Nanotubes or Graphene?, Advanced Materials, 25, Wiley, Weinheim, p.5153-5176

[16] Novoselov, K. S., Geim, A. K., Morozov, S. V., Jiang, D., Zhang, Y., Dubonos, S. V., Grigorieva, I. V., Firsov, A. A., 2004. Electric Field Effect in Atomically Thin Carbon Films, Science, 306 (5696): p. 666-669.

[17] APS News. Series II (2009) "This Month in Physics History: October 22, 2004: Discovery of Graphene".. 18 (9): 2. 2009. Available at: https://www.aps.org/publications/apsnews/200910/ph ysicshistory.cfm (Accessed: 10 September 2020)

[18] Wang, Y., Chen, Y., Lacey, S. D., Xu, L., Xie, H., Li, T., Danner, V.A., Hu, L., 2018. Reduced graphene oxide film with record-high conductivity and mobility, Materials Today. Vol 21, \#2, p. 186

[19] Murata, H., Nakajima, Y., Saitoh, N., Yoshizazwa, N., Suemasu, T., Toko, K., 2019. High-ElectricalConductivity Multilayer Graphene Formed by Layer Exchange with Controlled Thickness and Interlayer, Scientific Reports 9, Nature, 4068 https://doi.org/10.1038/s41598-019-40547-0
[20] Huang, C., Chen, J., Chiu, C. et al., 2016. Observing the evolution of graphene layers at high current density, Nano Res. 9, 3663-3670. https://doi.org/10.1007/s12274-016-1237-0

[21] Geim, A., Novoselov, K. 2007. The rise of graphene. Nature Mater 6, p. 183-191. https://doi.org/10.1038/nmat1849

[22] Nan, C.W., \& Shen, Y., Ma, J., (2010). Physical Properties of Composites Near Percolation. Annual Review of Materials Research. 40. 131-151. 10.1146/annurev-matsci-070909-104529.

[23] Wang, W., Wen, G. J., 2108. Electrical Conductivity of Carbon Nanotube-and Graphene-Based Nanocomposites, in "Micromechanics and Nanomechanics of Composite Solids" S.A. Meguid, G.J. Weng Editors. Springer, p.123 doi 10.1007/9783-319-52794-9

[24] Chen, Z., Ren, W., Gao, L., Liu, B., Pei, S., \& Cheng, H.-M. 2011. Three-dimensional flexible and conductive interconnected graphene networks grown by chemical vapour deposition. Nature Materials, 10, 424.

[25] Tran, T. S., Dutta, N. K., Choudhury, N.R., 2018. Graphene inks for printed flexible electronics: Graphene dispersions, ink formulations, printing techniques and applications, Advances in Colloid and Interface Science, Vol. 261, p. 41-61,

[26] Janas, D., Koziol, K.K., 2013. Rapid electrothermal response of high-temperature carbon nanotube film heaters, Carbon, Volume 59, p. 457-463

[27] Larciprete, M.C., Paoloni, S., Orazi, N., Mercuri, F., Orth, M., Gloy, Y., Centini, M., Li Voti, R., Sibilia, C., 2019. Infrared emissivity characterization of carbon nanotubes dispersed poly(ethylene terephthalate) fibers, International Journal of Thermal Sciences, Volume 146.

[28] Sun, H., Yang, Z., Lin, B., Shi, W., Zhu, Y., Zhao, H., 2020. Comparison of thermal comfort between convective heating and radiant heating terminals in a winter thermal environment: A field and experimental study, Energy and Buildings, Volume 224.

[29] Ampah, A.D., Pagone, E., Salonitis, K., 2019. Life Cycle Assessment of Graphene as Heating Element. In: Ball P., Huaccho Huatuco L., Howlett R., Setchi R. (eds) Sustainable Design and Manufacturing 2019. KES-SDM 2019. Smart Innovation, Systems and Technologies, vol 155. Springer, Singapore. https://doi.org/10.1007/978-981-13-9271-9_24

[30] Singh Ch, Shaffer MSP, Koziol KKK, Kinloch IA, Windle AH. Towards the production of large-scale aligned carbon nanotubes. Chem Phys Lett 2003; 372, 860-5 
2020-10-26

Carbon nanotubes and graphene radiant heater printed on a cementitious flooring substrate: a feasibility study

Patsavellas, John

SSRN

Patsavellas J, Salonitis K, Koziol K, et al., (2020) Carbon nanotubes and graphene radiant heater printed on a cementitious flooring substrate: a feasibility study. In: TESConf 2020 - 9th International Conference on Through-life Engineering Services, 3-4 November 2020,Online, Cranfield, UK

https://doi.org/10.2139/ssrn.3718072

Downloaded from Cranfield Library Services E-Repository 